\title{
Meconium periorchitis: A case report and literature review
}

\author{
Ammar Hameed Alanbuki, MD; Ashwith Bandi, MD; Nick Blackford, MD
}

Peterborough University Hospital, UK

Cite as: Can Urol Assoc J 2013;7(7-8):e495-8. http://dx.doi.org/10.5489/cuai.316

Published online July 2, 2013.

\section{Abstract}

Meconium periorchitis (MPO) is an uncommon entity associated with healed meconium peritonitis. The typical presentation is a soft hydrocele at birth which becomes harder in weeks as the meconium calcifies. A lack of awareness of this rare disease may lead to unnecessary surgery of scrotal masses. It can resolve spontaneously without compromising the testicle. Scrotal ultrasound is the mainstay of imaging and abdominal plain film is less sensitive but can help in the diagnosis. We report a case of a meconium periorchitis and discuss its radiological and histological features. We also review the relevant literature.

\section{Introduction}

Meconium periorchitis (MPO) is an uncommon benign cause of a scrotal mass in the newborn. ${ }^{1}$ In utero bowel perforation can be caused by thickened meconium associated with cystic fibrosis, bowel atresia, volvulus or vascular compromise. Leakage of meconium into the peritoneum causes meconium peritonitis (MP). Some bowel perforations heal without obvious sequelae and the baby appears well at birth. Meconium reaching the paratesticular soft tissue through a patent processus vaginalis causes a scrotal mass. ${ }^{2}$ The typical presentation is a soft hydrocele at birth which becomes harder in weeks as the meconium calcifies. Both the masses and the calcifications have the tendency to resolve spontaneously without compromising the testicle. It mimics a scrotal mass, and without knowledge of this rare disease, it may lead to unnecessary surgery. ${ }^{3}$

Radiologic evaluation with ultrasonic features and plain abdominal film may provide findings enough to suspect MPO. A normal testicle with this tumour-like lesion can differentiate it from scrotal tumours. ${ }^{4}$

\section{Case report}

We report a 2-month-old healthy term boy who was delivered normally after an uneventful pregnancy. The parents noticed a hydrocele for which case he was brought to the pediatric unit. A painless left scrotal mass was noted incidentally. The baby looked well and was feeding well; his scrotal mass was hard and localized, bilateral and clearly separable from the testis on examination and not tender to touch. The patient had normally descended testes and did not have any difficulty in the neonatal nursery, such as delayed passage of meconium or signs of bowel obstruction.

There were no signs of tenderness or erythema. According to the medical records, intrauterine ultrasonography at 20 weeks of gestation did not highlight any abnormality within the scrotal area.

Clinical laboratory studies, including urea and electrolytes, liver function test, serum alpha-fetoprotein and betahCG, were unremarkable.

Ultrasound scans during his admission demonstrated testes which were normal in shape, size and echopattern, with the right testis located within the inguinal canal. Within the right scrotum there was a mixed echogenic mass measuring $3.2 \times 1.4 \times 1.9 \mathrm{~cm}$. Doppler flow was noted within this mass. There was also a smaller mass on the left side measuring $1 \times 0.9 \times 0.9 \mathrm{~cm}$. Both kidneys were also scanned and were normal on ultrasound.

The patient was assessed in the urology clinic for 8 weeks after his first admission, with no resolution of these bilateral testicular masses, although it was thought that the peri-mass inflammation was settling. To clarify the matter, he underwent scrotal exploration. Intra-operatively, we found a circumscribed, firm paratesticular mass, which was adherent to the tunica vaginalis. The dissection was accomplished with some difficulty, as the patient also had a right inguinal herniotomy and orchidopexy. The postoperative course was uneventful. The boy was discharged the next day. 
Gross pathologic appearance confirmed a right oval soft lump measuring $2 \times 1.5 \times 1 \mathrm{~cm}$. The mass was finely calcified and had a variagated pale green cut surface. On the left side, an oval mass measured $1.5 \times 1 \times 0.3 \mathrm{~cm}$ with similar morphology to the right-sided sample (Fig. 1).

Microscopically the tissue composed of lobules of fibroconnective elements with abundant myxoid stroma, dystrophic calcification with scattered hemosiderin-laden macrophages, multinucleated giant cells and occasional squamous cells. These are the features of MPO (Fig. 2a, Fig. 2b).

\section{Discussion}

MPO was first described by Olnick and Hatcher in 1953 in an infant with scrotal and peritoneal calcification. ${ }^{5}$ It is a rare condition in infant boys who have had healed meconium peritonitis. The patient's age at the time of diagnosis of the associated mass varies, but patients typically present in the first months of life, but MPO has been reported in children up to 5 years old. ${ }^{6}$

Meconium is the greenish, viscous intestinal content of the distal small bowel present after the fourth month of fetal life. It contains swallowed amniotic fluid, bile salts, bile pigments, cholesterol, mucin, pancreatic enzymes, intestinal enzymes, squamous cells, lanugo hair and other cellular debris. $^{7}$

Meconium peritonitis occurs when a bowel wall rupture occurring during late fetal life or early postnatal life allows meconium to enter the peritoneal cavity. This may be associated with volvulus, bowel atresia or mesenteric vascular insufficiency. If the ruptured bowel wall heals, there may be no evidence of the cause or the site of perforation. This is called meconium peritonitis. ${ }^{8}$

Passage of the meconium through the patent processus vaginalis may result in MPO and the mass-like lesion arises because of an inflammatory reaction from meconium within the scrotal sac. The patent processus vaginalis is an evagi-

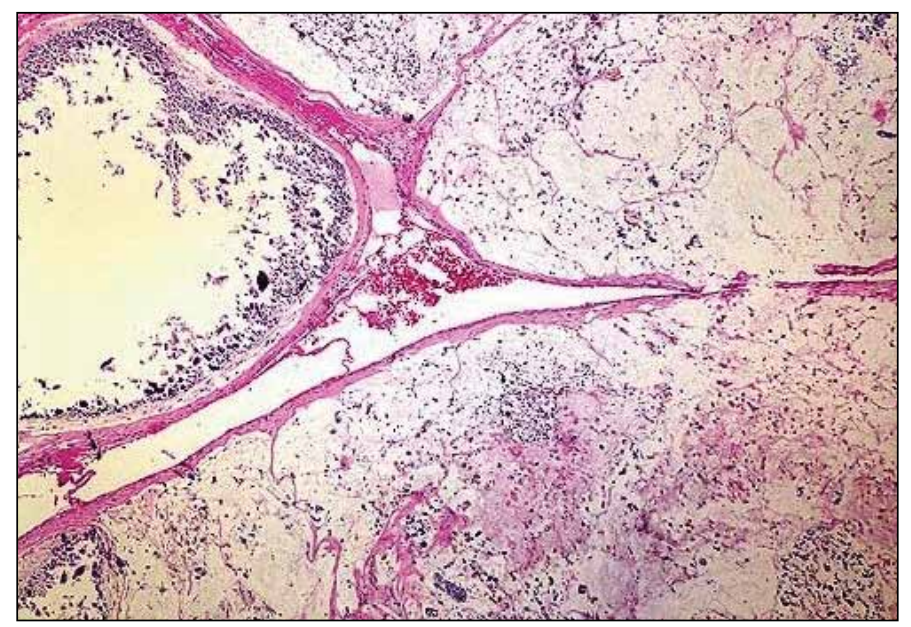

Fig. 2a. Lobules of fibroconnective tissue with abundant myxoid stroma.

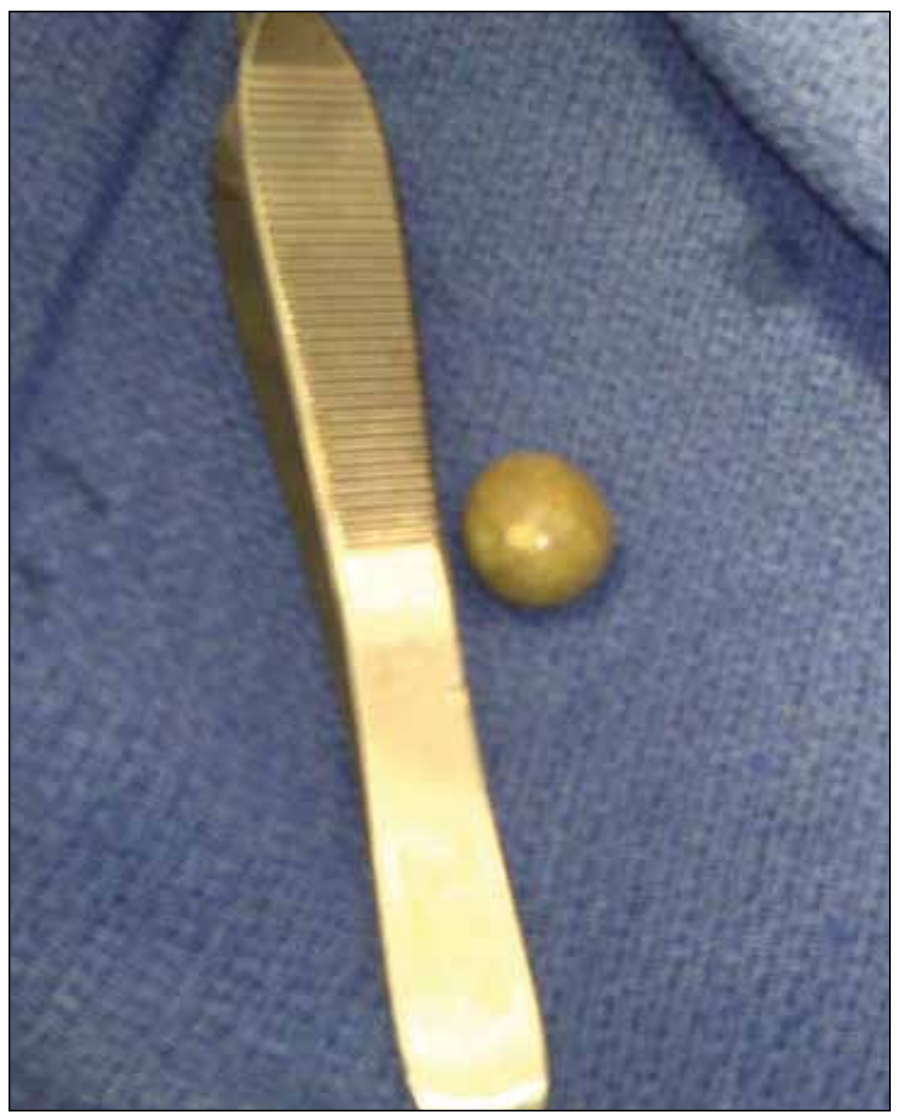

Fig. 1. Meconium periorchitis (gross appearance).

nation of the peritoneum from the ventral abdominal wall into the inguinal canal formed as the testis descends into the scrotum in the seventh month of gestation. The consistency and appearance of meconium in the scrotum evolve over time. The soft extratesticular mass at birth eventually hardens and becomes partially calcified. ${ }^{9}$

Our case represents a common clinical MPO in which the infant is clinically well, apart from the scrotal mass which is initially thought to be a hydrocele. Within weeks, the mass

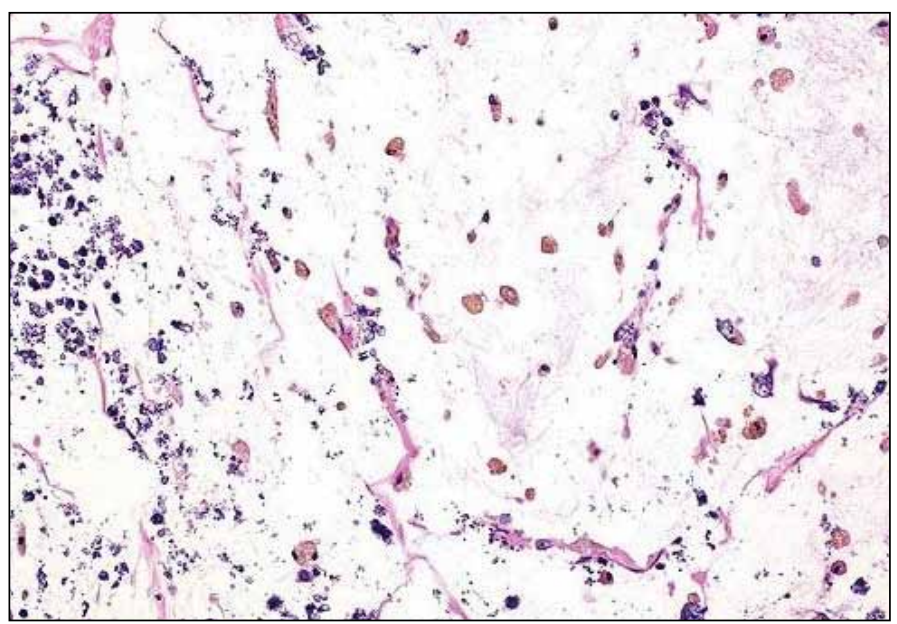

Fig. $\mathbf{2 b}$. Hemosiderin-laden macrophages and dystrophic calcification. 


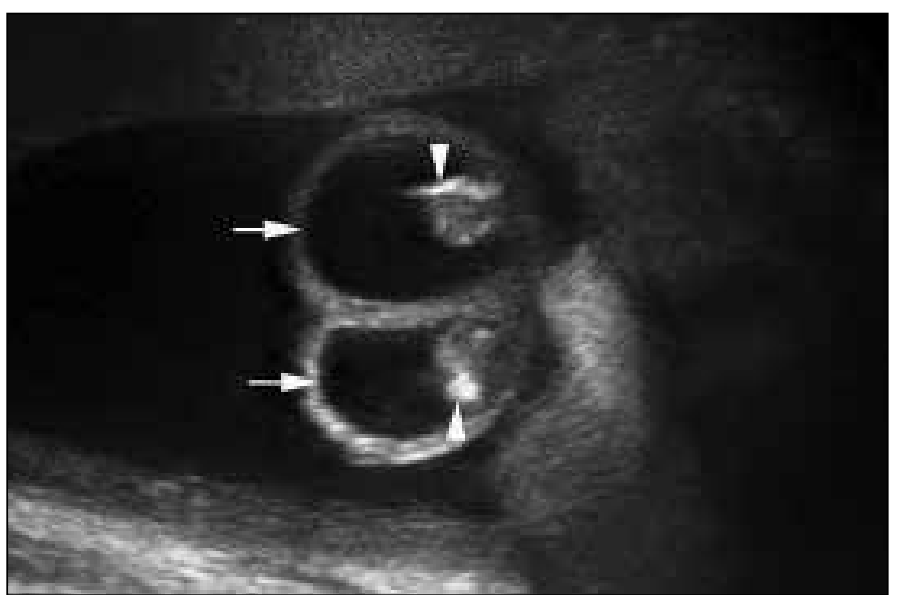

Fig. 3. Ultrasonic picture of meconium periorchitis.

calcifies and becomes hard, raising the suspicion of a neoplastic process of testicular or paratesticular tissue, particularly if firm and non-tender. Calcification at birth suggests that the perforation occurred earlier in gestation. Meconium in the peritoneal cavity initiates sterile, chemical foreign body peritonitis and causes foreign-body giant-cell reaction, chronic inflammation and, finally, scarring. ${ }^{7}$ Peritoneal calcifications follow and these classified masses in the scrotum can slowly resorb and do not require excision. ${ }^{10}$

Ultrasonography represents the favoured imaging technique due to it is ability to differentiate between the extra or intra testicular masses. Since most extra-testicular lesions are benign, while most intra-testicular lesions are malignant, it is importance to perform a preoperative ultrasonographic examination. On the other hand, abdominal radiographs may help to detect calcifications, it is absent in $10 \%$ of cases. ${ }^{10}$

It has been reported that $13 \%$ of cases had other congenital anomalies, including scrotoschisis, hypospadias, omphalocele and esophageal atresia. Cystic fibrosis, causing an thickened meconium and in utero bowel perforation, has been associated with MPO in $9 \%$ of cases, compared to $25 \%$ of neonates with meconium peritonitis. ${ }^{11,12}$

Prenatal detection of MPO has been reported in several cases. The differential includes an inguino-scrotal hernia, testicular torsion, an organizing hematoma and a tumour. ${ }^{13}$

Several scrotal masses, clinically present with calcifications, include mature teratomas, gonadoblastomas, calcifying clear cell Sertoli tumours, testicular microlithiasis, testicular torsion followed by hemorrhagic infarction, and metastatic neuroblastomas. These various clinical presentations cause huge confusion with a scrotal tumour and can result in unnecessary orchidectomy. Despite the benign nature of MPO, past studies indicated that unnecessary orchidectomies were performed in $18 \%$ of cases. ${ }^{14}$

\section{Role of ultrasound}

If present, sonographic findings of meconium peritonitis may help clarify the diagnosis. However, a triad of sonographic findings has previously been described in patients with meconium peritonitis, which included scrotal masses with calcifications, hydroceles and absence of blood flow to the peritesticular mass on Doppler studies. ${ }^{11}$ Our case did demonstrate blood flow to the peritesticular mass, which shows that it may not always be possible to manage these patients conservatively as histological confirmation is needed in such cases. However, we have to acknowledge that ultrasound is an operator dependant procedure and variations do exist.

\section{Conclusion}

When a peritesticular mass with calcifications and hydroceles is found on prenatal sonography, it is important to consider MPO and search for signs of meconium peritonitis. Atypical cases do occur, in which surgical exploration and histological confirmation are still warranted.

Competing interests: None declared.

This paper has been peer-reviewed.

\section{References}

1. Algaba F, Mikuz G, Boccon-Gibod L, et al. Pseudoneoplastic lesions of the testis and paratesticular structures. Virchows Arch 2007;451:987-97. http://dx.doi.org/10.1007/s00428-007-0502-8

2. Kalra P, Radhakhrishnan J. Meconium periorchitis. Urology 2006;68:202. http://dx.doi.org/10.1016/j. urology.2006.03.061

3. Brown-Harrison $M C$, Harrison $M$, Reid $B S$, et al. Meconium periorchitis - a cause of scrotal mass in the newborn. Clin Pediatr 2000;39:179-82. http://dx.doi.org/10.1177/000992280003900308

4. Williams $\mathrm{HJ}$, Abernethy $\mathrm{L}$, Losbty PD, et al. Meconium periorchitis a rare cause of a paratesticular mass. Pediatr Radiol 2004;34:421-3. http://dx.doi.org/10.1007/s00247-003-1079-2

5. Olnick HM, Hatcher MB. Meconium peritonitis. JAMA 1953;152:582-4. http://dx.doi.org/10.1001/ jama.1953.03690070016005

6. Kalra P, Radhakhrishnan J. Meconium periorchitis. Urology 2006;68:202. http://dx.doi.org/10.1016/i. urology.2006.03.061

7. Gilbert-Barnes E, Gunasekaran S. Male reproductive system. In: Gilbert Barnes E, editor. Potter's pathology of the fetus, infant and child. 2nd ed. Philadelphia: Mosby-Elsevier;2007:1414-26.

8. Sung T, Riedlinger WFJ, Diamond DA, et al. Solid extratesticular masses in children: Radiographic and pathologic correlation. AJR Am J Roentgenol 2006;186:483-90. http://dx.doi.org/10.2214/AJR.04.1895

9. Herman TE, SiegelMJ. Meconium periorchitis. J Perinatol 2004;24:53-5. http://dx.doi.org/10.1038/si.j.7211014

10. Dehner LP, Scott D, Stocker JT. Meconium periorchitis: A clinicopathologic study of four cases with a review of the literature. Hum Pathol 1986;17:807-12. http://dx.doi.org/10.1016/S0046-8177(86)80201-5

11. Careskey JM, Grosfeld JL, Weber TR, et al. Giant cystic meconium peritonitis (GCMP): improved management based on clinical and laboratory observations. J Pediatr Surg 1982;17:482-9. http://dx.doi.org/10.1016/S0022-3468(82)80094-8

12. Casaccia $G$, Trucchi $A$, Nahom $A$, et al. The impact of cystic fibrosis on neonatal intestinal obstruction: the need for prenatal/neonatal screening. Pediatr Surg Int 2003;19:75-8.

13. Wax JR, Pinette MG, Cartin A, et al. Prenatal sonographic diagnosis of meconium periorchitis. J Ultrasound Med 2007;26:415-7. 
Alanbuki et al.

14. Dehner LP, Scott D, Stocker JT. Meconium periorchitis: a clinic-pathologic study of four cases with a review of the literature. Hum Pathol 1986;17:807-12. http://dx.doi.org/10.1016/S0046-8177(86)80201-5
Correspondence: Mr. Ammar Hameed Alanbuki, Specialist Registrar Urology, Peterborough University Hospital, UK; dr_ahameed@hotmail.com 